\title{
Researching on Operating System Course Teaching of Applied Universities
}

\author{
Wang Xiaojie ${ }^{1, a}$ Ding Linhua ${ }^{1, b}$, Wang Jiuru ${ }^{1, c}$, \\ ${ }^{1}$ School of Informatics, LinYi University, Linyi 276000, China \\ aemail:wangxiaojie@lyu.edu.cn, bemail:private_ding@163.com, cemail:wangjiuru@lyu.edu.cn
}

Keywords: Computer Operating System; Applied University; Teaching Reform

\begin{abstract}
Computer operating system is the core and also the foundation of computer system software, so operating system course is an integrated basic course. But for students, this course is very abstract and miscellaneous so as to be difficult understand. At the same time, the teaching content is difficult to link with the experiments that leads to that it is difficult for students to realize the importance of this course. This paper introduces how to help students to understand the principle of operating system, to realize the importance of this course, how to let the operating system course closely connected with the practical application to improve the students' interest. In order to adapt to the need of applied talents training, computer operating system course should adjust the teaching content, reform the practice teaching, in order to training applied programing talents with high quality of practical ability and innovative ability.
\end{abstract}

\section{Introduction}

Computer operating system is the most basic computer system software and the core of the computer software system. Design principle and realization of the computer operating system is the basic knowledge that related professional students must master. As a professional basic course and degree courses, operating system is one of the postgraduate exam course, is also one of the doctoral examination subjects. But at the same time, the characteristic of the course is very abstract and its' content is difficult to link with the experiments. So for students, it is difficult to understand and difficult to realize the importance of course. So many students and teachers think that this course is not necessary in applied college and university. How to make students realize the importance of this course from practice, understand and master the basic principle and implementation technology of the operating system, and how to strengthen the engineering practice ability, team cooperation ability and innovation consciousness of students, is a very big challenge. This paper helps students to understand the principle of operating system, to realize the importance of the course, and improves the students' interest. In order to adapt to the need of applied talents training, computer operating system course should adjust the teaching content, reform the practice teaching, in order to training applied programing talents with high quality of practical ability and innovative ability.

\section{The Main Difficulties and Problems of the Course Teaching}

Firstly, according to the different management functions of the operating system, the course is divided into process management, job management, storage management, file management, equipment management and so on several parts. Teachers often explain a certain part, so students are difficult to establish the concept and fuse related knowledge of the whole system.

The logic of operating system itself is very tight, so student's understanding of some of the management functions is not enough. Students must effectively grasp the whole operating system, in order to better understand and grasp the whole course, to build perfect knowledge structure, and to cultivate the strong consciousness of software engineering.

Secondly, the operating system is a systematic professional foundation course. This course is a comprehensive course, and its content has crossed with many courses, such as programming, data structure, assembly language, compiler theory, computer composition principle, etc. Student's 
understanding and master of precursor course will directly affect the study of the operating system.

Thirdly, the theory of this course is strong, and practice content and scenarios is lack. This problem is a major cause to make the applied professional students feel the operating system is useless. Because there are too much content of the operating system course, and the teacher often Concentrate on theoretical interpretation in teaching, ignore to cultivate the students' practical ability. Teachers often think that the student can't design an operating system really, so the experiment arrangement of this course is basically the verification experiment, also cannot provide students more updated experimental platform. The contents of this course can't use real connection with the current operating system, that lets students feel the course is abstract and boring, and even think learning this course is useless.

Finally, operating system technology is developing rapidly. At present, the operating system development in multiple directions such as the multi-channel, multi-core, microkernel, embedded, distributed, multiprocessor. At present, there are many different popular operating system on the market such as the Unix, Linux, Windows, Mac, IOS and Android, and other mainstream operating system. Most teachers can't put the principle, technology and application of the current operating system to the teaching of the course, that makes the teaching content can't adapt to the development of the theory and technology. Most of the teachers did not add the latest theory and application of the operating system to the teaching content. If the theoretical teaching could be combined with frontier knowledge of operating system, it will greatly improve the students' interest.

\section{Strengthen Cohesion between the Knowledge Points of the Teaching Content}

On the one hand, in order to improve the teaching quality of the operating system, we should to strengthen the connection between the knowledge points.

In order to let the students to grasp the whole operating system effectively, establish perfect knowledge structure under the guidance of teachers, we draw the chapters "knowledge diagram" of knowledge points, such as the following Fig.1. When knowledge diagram of the whole course is finished, students will be able to come to the conclusion that each section of the operating system has inner relations with other knowledge points, and realize the overall grasp of knowledge, association memory and orderly arrangement. Then the students can draw the tree of knowledge, even are able to discus and analyze, and explore knowledge independently.

On the second hand, we should strengthen connection with other precursor and the subsequent courses.

First, strengthen the connection with programming language design courses. Programming language is a precursor of the operating system course. For example, there are a lot of the operating system of theory and experiment in $\mathrm{C}$ language, such as control structure, functions, arrays, pointers, and the contents of the file operations, etc. In addition, the code reading and analysis ability is also a very important aspect. Teachers could focus on those contents related with implementation of the operating system such as function pointer, etc. 


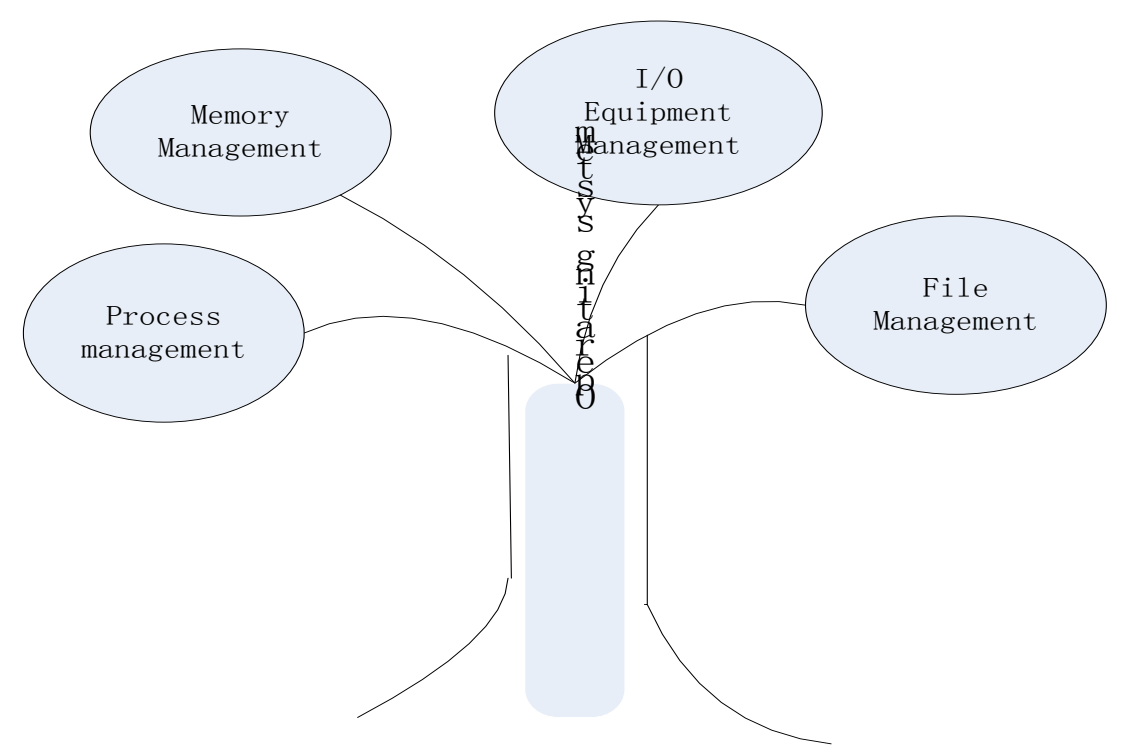

Fig.1. knowledge diagram of Operating system

Second, strengthen the connection with the data structure course. The teaching contents of Data Structure course is the basic data structure and their algorithm, which has very important significance to understand the implementation of specific function of the operating system. Data structure is more closely linking to the operating system, including the concept of data structure such as string, list (including two-way chain table), Hash table, binary tree, file structure, and including associated important algorithms such as string operations, list of basic operation (such as insert, sorting), binary tree traversal, external sort, etc. Firmly grasping and understanding the knowledge of the data structure and algorithm is great significance for the operating system. In the practice of data structure course teachers should focus on strengthening aspects such as linked lists, two-way chain table and the practice of teaching. In addition, we also modest strengthen (about 4 hours) Hash table and multi-dimension linked list.

Third, strengthen the connection with the course of computer composition principle course. Computer composition principle course is the first course in the direction of computer hardware. The main content of it is interpreting the working principle of independent components of the computer system structure. Some parts of this course have strong connection with the operating system course, which mainly reflects in the interrupt mechanism, equipment management, IO control, DMA, the actual address translation and other aspects. Teachers should focus on these chapters associated with the operating system course when teaching courses of computer composition principle.

In addition, there is always some repetitive knowledge and related disciplines in different courses. The teacher must increase their knowledge, so they can teach from different aspects for each class.

On the third hand, we should strengthen the connection with practice.

Interesting is the best teacher, the practice is the best method of study. The practice teaching of applied talents and innovative talents has a very important role. The core of the experimental teaching is to cultivate students' practical and innovative ability.

For the operating system platform used in the experiments, we choose Windows, Linux, and Android, and many other experimental platform. The reason of selecting Windows platform is that many applications are based on the Windows, so that students will easily learn more course knowledge and better combine with the actual work in the future. Currently, mobile platform widely applied in the production and life, so let the student understand mobile operating system platform and preliminary control based on the development of mobile operating system platform is very important. At present, mobile systems widely applied is embedded Linux, Android, Symbian, iOS and VxWorks, etc. In our teaching and experiments, we choose the Android mobile platform.

On the fourth hand, we should strengthen the connection with the latest achievements.

How to cultivate creative ability of college students is an important topic of the applied university faces. Combining the latest achievements of science and technology and experiment 
plays an important role to cultivate the students' research consciousness, innovative thinking, work ability and scientific quality.

Multi-core processors now are popular, so we can discuss the operating system with multi-core processors in the course more and more. Cloud computing is much hyped, so we discuss cloud operating system in the course. In addition, considering the safety of the operating system about national informatization construction, we also discuss the development of domestic operating system and so on.

On the other hand, we should strengthen the connection with graduation design.

Graduation design is the students' knowledge integration and simulation of four years. The study and practice of each course is likely to be a starting point of graduation design. In the process of teaching, teachers pay attention to combine the operating system research with practice and graduation design to guide students to make a good design.

\section{Reform Teaching Method and Examination Mode}

In classroom teaching, we use case driven method and problem driven method, which not only arouse the enthusiasm of the students, but also cultivate students' good habit of active thinking. We attach great importance to cultivate the students' team cooperation spirit, encourage students to collaborate to complete large operations. In the process of teaching, we use team-learning, case analysis, field research and simulation methods of training, training students' ability to solve practical problems. In practice, we have sufficient experimental materials for students, divide the students into different experimental group to carry out an experiment projects, in order to cultivate the students' team cooperation spirit.

In the aspect of teaching material, not only use only one textbook, but recommend both Chinese and English books as references book for the students. Let the student can look at the same problem from different books of different content and different point of view.

In terms of the inspection way, we have changed the previous method which only goes for the final exam. Change the students' academic performance to the mid-term exam achievement, course practice, the final exam scores and grades. Research results are also included in the grades of students.

\section{Other measures}

The development of bilingual teaching is to cultivate the students' ability to understand, track, frontier hot and knowledge, improve the students' English reading and comprehensive skills. In the process of the implementation of bilingual teaching, we emphasis the teachers should make efforts to build a "rather than to learn English in English environment, pay attention to cultivate students ability of applying English professional technology, but not in order to reduce the teaching quality of specialized courses for bilingual teaching in the form of the exchange.

We organize students to take an active part in ACM competition, mathematical modeling contest, and other all kinds of competitions. Students can continuously hone in the competition and improve the ability of hands-on practice and solving the problem. At the same time, we also set up open laboratories for the students.

We provide independent learning platform for students. Students can view the syllabus, textbooks, reference books, the experiment instruction, courseware and learning video to coaching, answering questions, discussion, self-test system and submitting assignments and other activities. It has a very positive role for the teacher auxiliary teaching, to create a good environment for students' autonomous learning.

\section{Conclusion}

In terms of applied universities, cultivating students' practice ability and quality has become a top priority of teaching. In order to achieve the expected teaching effect, determine the important 
position of professional system for the operating system, we must be given to the operating system of teaching contents, teaching methods reform strategy, and use a variety of auxiliary measures to help students build a solid platform for the theory and practice, cultivate students' research consciousness, innovative thinking and ability to apply.

\section{References}

[1] Andrus J, Nieh J. Teaching operating systems using android[C]//Proceedings of the 43rd ACM technical symposium on Computer Science Education. New York: ACM, 2012: 613-618.

[2] Cohen S. Teaching Operating Systems Scheduling[C]//Proceedings of informing Science and IT Education Conference.Cassino: Informing Science Institute, 2010: 609-619.

[3] Stallings W. Operating systems internals and design principles [M]. 7th ed.Beijing: Pubulishing house of Electronic industry, 2012: 218-300.

[4] Computer Science Curricular 2013(Ironman Draft)[EB/OL]. (2013-09-12) [2013-12-06]. http://ai.stanford.edu/users/sahami/CS2013/ironman-draft/cs2013-ironman-v1.0.pdf.

[5] Zhaoqingshui,Shenlimin.Researches and Practice of Teaching and Management Model Based on Flexibility [J]. computer education2008, (18) 42-44.

[6] Aviv A J,Mannino V,Owlarn T,et al.Experiences in teaching an educational user-level operating systems implementation project[J].ACM SIGOPS Operating Systems Review,2012,46(2):80-86. 